\title{
Long-term Cycles in the 0cean Carbon Reservoir: Records From the South China Sea
}

Pinxian Wang, Jun Tian and Xinrong Cheng

Key Laboratory of Marine Geology, Ministry of Education, Tongji University, Shanghai 200092, China; pxwang@mail.tongji.edu.cn

The carbon isotope sequence at ODP Site 1143, southern South China Sea reveals a 400-500 kyr long-term cyclicity that is superimposed on glacial cycles and present in long $\delta^{13} \mathrm{C}$ sequences from all oceans. As seen from Figure 1, the Quaternary $\delta^{13} \mathrm{C}$ record is punctuated by four $\delta^{13} \mathrm{C}$ maximum events: $\delta^{13} \mathrm{Cmax}-\mathrm{I}$ (from MIS 3 around 5060 kyr onward), $\delta^{13} \mathrm{Cmax}-I I$ (MIS 13 , 470-530 kyr), $\delta^{13} \mathrm{Cmax}-$ III (MIS 25-28, 0.95-1.00 myr) and $\delta^{13} \mathrm{Cmax}-\mathrm{VI}$ (MIS 53-57, 1.55-1.65 myr], while the earlier $\delta^{13} \mathrm{C}$ maximum events occur at the long eccentricity minima with a regular $400 \mathrm{kyr}$ periodicity. As the same periodicity is also found in carbonate curves, the $\delta^{13} \mathrm{Cmax}$ events denote major reorganization in carbon reservoirs of the global ocean.

Shifts in carbon reservoirs at the times apparently affecting global climate, and at least two $\delta^{13} \mathrm{Cmax}$ events led to major changes in glacial cyclicity: $\delta^{13} \mathrm{Cmax}-\mathrm{Il}$ led to the Mid-Brunhes Event (MBE) and $\delta^{13} \mathrm{Cmax}-\mathrm{III}$ to the Mid-Pleistocene

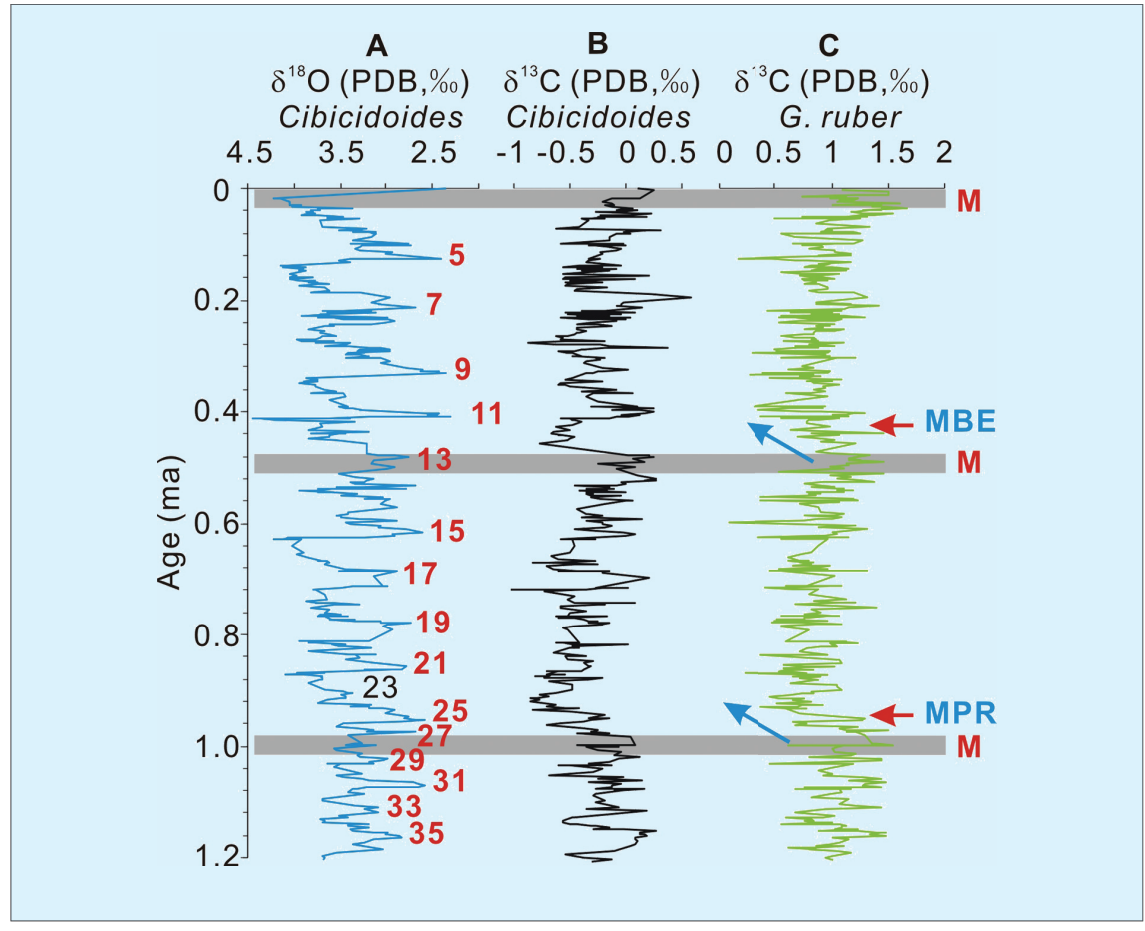

Fig. 2: Oxygen and carbon isotopic records spanning 1.2 myr from ODP Site 1143. (A) benthic $\delta^{18} \mathrm{O} ;(\boldsymbol{B})$ benthic $\delta^{13} \mathrm{C} ;(\boldsymbol{C})$ planktonic $\delta^{13} \mathrm{C}$. Numbers labeling $\delta^{18} \mathrm{O}$ curve indicate marine oxygen isotope stages (MIS), grey bars denote carbon isotope maximum $\left(\delta^{13} \mathrm{Cmax}\right), \mathrm{MBE}$ stands for Mid-Brunhes Event, MPR for Mid-Pleistocene Revolution. Arrows show that $\delta^{13} \mathrm{Cmax}$ preceded the transition in glacial cyclicity and expansion of ice-sheet.

Revolution (MPR) (Fig.2). At the beginning of the Mid-Brunhes Event, ca. $430 \mathrm{kyr}$ ago, the global ocean

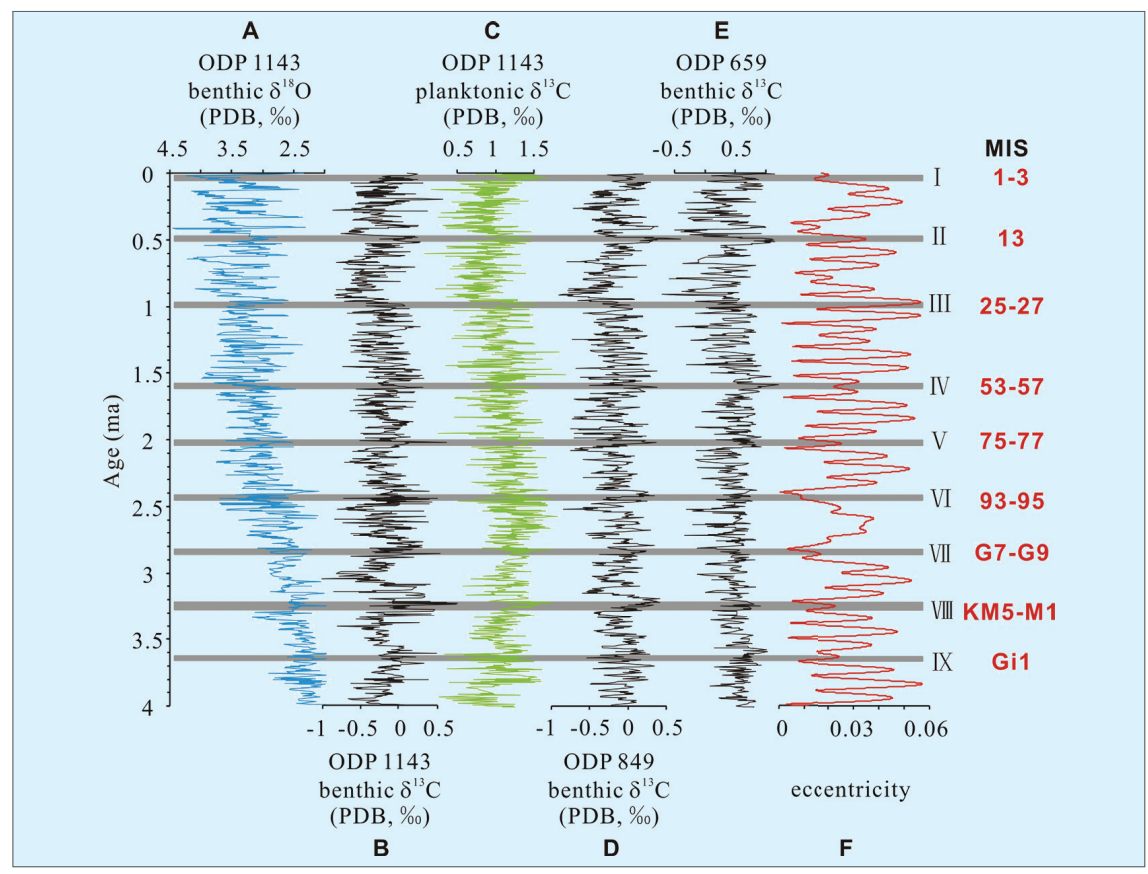

Fig. 1: Carbon isotope records over the last 4 Ma. ODP 1143, South China Sea: (A) benthic $\delta^{18} O$, (B) benthic $\delta^{13} \mathrm{C}$; (C) plankton $\delta^{13} \mathrm{C}$. Eastern Pacific: (D) ODP 849 benthic $\delta^{13} \mathrm{C}$. Northern Atlantic: (E) ODP 659 benthic $\delta^{13} \mathrm{C}$. (F) eccentricity. Gray bars denote carbon isotope maximum events $\left(\delta^{13} \mathrm{Cmax}\right)$ showing $400-500$ ka periodicity, and $\delta^{13} \mathrm{Cmax}$ corresponds to eccentricity minimum (k) before the Quaternary. I-IX on the right show the succession of $\delta^{13} \mathrm{Cmax}$. experienced the largest amplitude change in $\delta^{18} \mathrm{O}$ over the past 6 myr. This $\delta^{18} \mathrm{O}$ event recorded a major expansion of ice sheet size, which cannot be explained by the small changes in orbital forcing, but is preceded by $\delta^{13} \mathrm{Cmax}-\mathrm{II}$. The $\delta^{13} \mathrm{Cmax}-\mathrm{Il}$ event was marked by extremely warm and humid conditions in the low latitudes around the world: an exceptional ${ }^{18} \mathrm{O}$-depletion peak in the equatorial Indian Ocean, abnormal occurrence of a thick sapropel layer in the Mediterranean, extremely heavy precipitation and erosion in the Amazon drainage basin, and unusually deep weathering in the Loess Plateau. This climate event was accompanied by widespread changes in the upper ocean structure and in phytoplankton productivity, and obviously resulted in disturbance in carbon reservoirs that in turn led to major growth of ice-sheet size. Similar events happened during $\delta^{13} \mathrm{Cmax}$ III at about 1.0 myr, and again the drastic changes in carbon reservoir 
preceded the Mid-Pleistocene revolution at 0.9 myr when the boreal ice sheet increased in size and the prevailing glacial cyclicity changed from $\sim 40 \mathrm{kyr}$ to $\sim 100 \mathrm{kyr}$.

Before the Quaternary, $\delta^{13} \mathrm{Cmax}$ usually occurred at times of minimal eccentricity forcing, and the long term-variations in $\delta^{13} \mathrm{C}$ and $\delta^{18} \mathrm{O}$ display the same $400 \mathrm{kyr}$ cycles; but in the Quaternary, $\delta^{13} \mathrm{Cmax}-\mathrm{Il}$ and $\delta^{13} \mathrm{Cmax}$-III are out of phase with this astronomical cycle (Fig.1). Therefore, prior to the formation of large ice sheets in the Northern Hemisphere, $\delta^{13} \mathrm{C}$ co-varied with $\delta^{18} \mathrm{O}$ in the ocean records but in Quaternary times the 400-kyr cyclicity waned in the $\delta^{18} \mathrm{O}$ records and apparently "stretched" into 500 kyr in $\delta^{13} \mathrm{C}$.

The origin of the $\delta^{13} \mathrm{Cmax}$ episodes in the Quaternary and the nature of the long-term cycles remain unclear. Our working hypothesis suggests that the long-term cycles in weathering intensity in tropical areas may give rise to increased flux of Si from land to ocean, which may change the diatom/coccolith ratio in phytoplankton and subsequently the organic/inorganic carbon ratio in sediments. There is strong evidence for the 400-kyr cyclicity in monsoon climate and in opal production in the ocean that is well-correlated with the $\delta^{13} \mathrm{C}$ record. However, more work is needed to find out the mechanism behind the observed changes in carbon cycling. A common practice in Quaternary climate history studies is just to peruse ice-volume variations as exhibited by $\delta^{18} \mathrm{O}$, by considering carbon system changes as the consequences of ice-volume changes. The new discovery shows that long-term changes in carbon reservoirs on the Earth have their own periodicity and their own history, and do not simply follow ice cap variations in the Northern Hemisphere. The Quaternary period has passed through three major stages defined by four $\delta^{13} \mathrm{Cmax}$ events, and each appears to represent a further step in icecap development. Now the Earth is passing through a new carbon isotope maximum, $\delta^{13} \mathrm{Cmax}-\mathrm{I}$. It is therefore crucial to understand the physical and climatic significance of the long-term carbon cycles, if we are to predict the natural long-term changes of global climate.

\section{REFERENCES}

Wang P, Tian J, Cheng X, Liu, C., Xu, J., 2003. Carbon reservoir change preceded major ice-sheets expansion at Mid-Brunhes Event. Geology, 31: 239-242.

Wang P, Tian J, Cheng X, Liu, C., Xu, J., 2003. Exploring cyclic changes of the ocean carbon reservoir. Chinese Science Bulletin, 48: 2536-2548.

Wang P, Tian J, Cheng X, Liu, C., Xu, J., 2004 Major Pleistocene stages in a carbon perspective: The South China Sea record and its global comparison. Paleoceanography, 19, PA4005, dio: 10.1029/2003PA000991

\title{
A 1437-year Precipitation History From Qilian Juniper in the Northeastern Qinghai-Tibetan Plateau
}

\author{
Xuemei Sha0 ${ }^{1,2}$, Eryuan Liang ${ }^{2}$, Lei Huang ${ }^{1}$ and Lily Wang ${ }^{1,2}$ \\ IInstitute of Geographical Sciences and Natural Resources Research, CAS, Beijing 100101, China; shaoxm@igsnrr.ac.cn \\ ${ }^{2}$ Institute of Tibetan Plateau Research, CAS, Beijing 100085, China
}

High-resolution proxy records of climate spanning multiple millennia are needed to understand natural climate variability of the past. The native Qilian juniper (Sabina przewalskii) growing in the mountains of arid and semi-arid areas in the northeastern Qinghai-Tibetan Plateau exhibits a great potential for climate reconstruction. Based on well-replicated and cross-dated specimens from living trees from 11 sites (Fig. 1) at Delingha, Wulan and Tianjun, Qinghai Province, a 1600-year-long regional composite ring-width chronology was developed. This chronology was compared with the Dulan chronology (Zhang, et al., 2003), which is located approx. 65-150 km south of our sites. It was found that there were two more rings in our chronology than in the Dulan chronology in the common interval of AD 404-2000. One ring occurred at either AD 874 or 875, and another one at AD 711, rather than at AD 682 as indicated

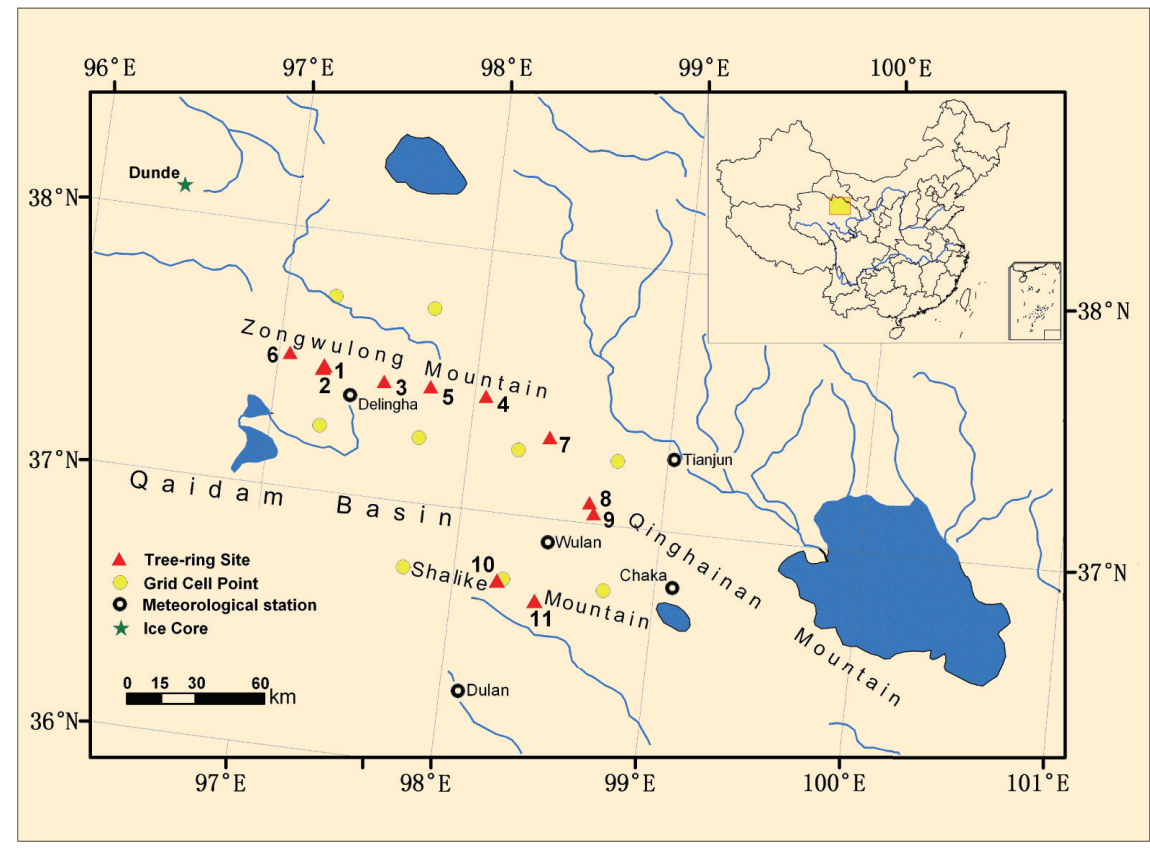

Fig. 1: Location of tree-ring sites, grids of precipitation data and meteorological stations.

by Tarasov et al. (2003) and Sheppard et al. (2004). Besides the reconstruction of past climate as reported here, this multi-site chronology will serve as the master chronology to cross-date archeological specimens excavated from tombs of the Tubo Kingdom in Delingha County, a potential that has been demonstrated by Sheppard et 